\title{
"Viva la Parola!”: a constituição de verdades acerca da educação de surdos no congresso de Milão (1880)
}

\section{"Viva la Parola!": The constitutions of truths on the education of the deaf in the Milan conference (1880)}

\author{
José Raimundo Rodrigues* \\ Lucyenne Matos da Costa Vieira-Machado* \\ Eliane Telles de Bruim Vieira*
}

\begin{abstract}
RESUMO
Este texto tem como objetivo discutir a História da Educação dos sujeitos surdos a partir da leitura de quatro documentos que relatam o "Congresso Internacional Para o Melhoramento do Destino dos Surdos-Mudos" ocorrido em Milão, na Itália, de 6 a 11 de setembro de 1880, mais conhecido como “Congresso de Milão". No conjunto de congressos acerca da temática da educação dos surdos, esse congresso torna-se o mais conhecido e, por isso, permanece como documento-monumento na área. A partir de uma leitura do corpus documental desse evento, procuramos retomar como, em Milão, se deu a construção de uma verdade a ser implementada. Para tal empreendimento, problematizamos como as bases religiosas e filosóficas da época permitiram normatizar o melhor método para a educação de surdos. Essa análise do conjunto de documentos referentes ao "Congresso de Milão" favorece discutir questões ainda hoje subjacentes em muitos debates acerca da educação de surdos.
\end{abstract}

Palavras-chave: Educação de surdos. Congresso de Milão (1880). Método oral puro.

*Universidade Federal do Espírito Santo. Vitória, Espírito Santo, Brasil. E-mail: educandor@ gmail.com - https://orcid.org/0000-0002-3922-1105 E-mail: lumatosvieiramachado@gmail.com - https://orcid.org/0000-0002-7385-6243 E-mail: ebruim@yahoo.com.br - https://orcid.org/00000002-3247-1822 


\begin{abstract}
This study aims at discussing the History of Education of the deaf out of the reading of four documents which report the "International Congress for the Improvement of the Destiny of the Deaf" (Second International Congress on Education of the Deaf) held in Milan, Italy, from September 6th to September 11th, in 1880, also known as the "Milan Conference." In a series of conferences regarding the education thematic of the deaf, the aforementioned congress becomes the most commonly known one and, thus, remains a document-monument in the study field. From reading the documental corpus of such events, we sought to recapture how the construction of an implemented truth happened in Milan. To carry on such endeavor, we problematized how the philosophical and religious bases of that time allowed the best method of normalization for the education of the deaf. The analysis of the set of documents concerning the "Milan Conference" favors the discussion of matters that are still subjacent in many debates on the education of the deaf nowadays.
\end{abstract}

Keywords: Education of the Deaf. Milan Conference (1880). Pure Oral Method.

\title{
"Abre-te!"
}

Ao final do século XIX, o ritual católico do sacramento do batismo nas catedrais europeias previa um gesto singular: após ser derramada a água benta sobre a criança, simbolizando esse gesto o nascimento dela como filha de Deus, o sacerdote tocava os ouvidos e os lábios do infante e pronunciava: "Efatá!".

Inspirada na ação de Jesus ao curar um surdo-mudo narrada pelos evangelhos, a realização do ato no sacramento apelava para a capacidade do novo cristão de ouvir a boa nova e de ser capaz de anunciá-la. "Abre-te!"

Após alguns poucos anos, no entanto, muitas famílias se deparavam com o fato de terem filhos surdos. Como educar essas crianças? Como conduzilas? No século XIX, as instituições europeias que se dedicavam à educação de surdos experimentavam práticas diversas, e, num ímpeto de homogeneizar ações, professores de surdos organizavam congressos para discutir o melhor método a ser utilizado.

"Abre-te!" foi também o desejo dos participantes do "Congresso Internacional para o melhoramento do destino dos Surdos-Mudos", ocorrido em Milão, na Itália, de 6 a 11 de setembro de 1880. Nele, modificaram-se os surdos-mudos em surdos-falantes. 
Muitos trabalhos já discutiram "Milão" e focaram nas deliberações do evento. Partimos do pressuposto de que, em "Milão", a decisão pelo método oral puro foi prévia. Interessa-nos, portanto, compreender como os participantes, já simpatizantes de tal método, utilizaram aquele espaço para a configuração dessa verdade que veio a ser proclamada de forma inquestionável.

Ponderamos essa impossibilidade de questionar a decisão em função da prática social da época. Por meio de congressos, eram convocados interessados e estudiosos sobre um determinado tema. Nesses eventos eram apresentadas decisões que, após votadas, viriam a ser implantadas. No caso específico de "Milão", é importante perceber como a delegação enviada pela França teve interesse em saber da decisão dos congressistas, objetivando impor uma verdade educacional que validasse futuras decisões dos Ministérios do Interior e da Instrução.

O relatório de Adolphe Franck parece ter sido determinante para tal empreitada.

Para que as nossas análises tornassem possível este trabalho, fizemos uso dos escritos de Michel Foucault e de suas noções de verdade e de documentomonumento, pois entendemos ser interessante fazer uma análise monumental e documental do "Congresso de Milão" de 1880:

Digamos, para resumir, que a história, em sua forma tradicional, se dispunha a "memorizar" os monumentos do passado, transformá-los em documentos e fazer falarem estes rastros que, por si mesmos, raramente são verbais, ou o que dizem em silêncio coisa diversa do que dizem; em nossos dias, a história é o que transforma os documentos em monumentos e que desdobra, onde se decifravam os rastros deixados pelos homens, onde se tentava reconhecer em profundidade o que tinham sido, uma massa de elementos que devem ser isolados, agrupados, tornados pertinentes, inter-relacionados, organizados em conjunto (FOUCAULT, 2014b, p. 8).

Segundo Foucault (2014a, p. 288), “(...) as pessoas são mais livres do que pensam, que elas tomam por verdadeiros, por evidentes certos temas fabricados em um momento particular da história, e que essa pretensa evidência pode ser criticada e destruída". Seguindo a mesma linha de pensamento, baseada na análise dos estudos foucaultianos, Paraíso (2012, p. 27) aborda que "a verdade é uma invenção, uma criação. Não existe a verdade, mas, sim, regimes de verdade, isto é, discursos que funcionam na sociedade como verdadeiros".

Nesse contexto, por meio de uma análise do corpus documental, desejamos problematizar como, nos documentos que nos permitem acessar o "Congresso de 
Milão", é possível visualizar a constituição de uma verdade que teve profundo impacto na história da educação de surdos ao considerar apenas o método oral puro como ideal e legítimo.

O presente texto, além da introdução e das considerações finais, divide-se em quatro partes: na primeira, trataremos dos aspectos históricos e metodológicos; na segunda, abordaremos a justificativa de um congresso em Milão; na terceira, refletiremos sobre os conteúdos tratados; e, na quarta, trataremos das bases religiosa e filosófica que sustentaram a decisão maior do evento.

\section{Milão: um monumento em vários documentos}

Às vésperas dos 140 anos do "Congresso de Milão", retomar a sua leitura é no mínimo necessário, afinal, grande parte da narrativa hegemônica sobre a história da educação dos surdos se dá a partir das decisões favoráveis ao método oral puro como o melhor método de ensino da palavra ao surdo.

Concordamos com Robin (2016, p. 31) quando a autora afirma que: "o passado não é livre. [...]. Ele é regido, gerido, preservado, explicado, contado, comemorado ou odiado." Por esse passado, estamos dispostos a tudo; lutamos pela sua memória ou para o seu apagamento.

$\mathrm{E}$, mesmo que surja uma nova conjuntura, um novo horizonte, muitas vezes voltamos, apagamos, ignoramos ou mesmo reescrevemos e reinventamos a história. As sociedades não o deixam a mercê e, sendo ocultado ou celebrado, não importa, o presente se alimenta dele (ROBIN, 2016).

Seguimos com Paul Ricouer quando o autor afirma: "Eu fico confuso com o espetáculo inquietante que transmite aqui o excesso de memória, e o excesso de esquecimentos em outros lugares, para não dizer nada da influência das comemorações e dos abusos da memória e do esquecimento" (apud ROBIN, 2016, p. 32). Dialogamos com Ricoeur pois também somos interpelados quando percebemos que há um invólucro sobre a narrativa da existência de "Milão" como um único congresso que decidiu TODOS os rumos da educação dos surdos nos séculos XIX e XX.

Essa áurea, que cria inúmeros imaginários possíveis sobre o que realmente aconteceu nos dias que transcorreram o evento, invisibiliza toda uma história que envolve as decisões tomadas tanto nesse congresso como naqueles que o antecederam, além de afetar os congressos subsequentes. E, ainda no século XIX, deu ênfase às disputas de narrativas, à própria desconstrução ou afirmação da verdade enunciada em "Milão": que o método a ser seguido pelos professores 
para o melhoramento da sorte dos surdos-mudos é o método oral puro, afinal é o que os tornaria surdos-falantes.

Com participação majoritária de professores franceses e italianos, o "Congresso de Milão" se deu entre os dias 06 e 11 de setembro de 1880 na cidade de Milão (Itália). Leandro Calbente Câmara (2018) afirma que "mais da metade dos participantes eram italianos e entre um terço e um quarto eram franceses. Os demais 15\% eram compostos por ingleses, americanos, suecos e suíços" (CÂMARA, 2018, p. 272). Com exceção de dois surdos estrategicamente convocados para o evento, eram ouvintes todos os congressistas que propunham discutir o melhor método para a educação de surdos.

As decisões do "Congresso de Milão" podem ser conhecidas por ao menos quatro documentos distintos. Apesar de terem elementos em comum, é inegável que somente uma leitura conjunta desses documentos permite compreender a complexidade de "Milão".

O documento mais popularizado no Brasil é a versão elaborada por Arthur Alfred Kinsey (1850-1888), responsável pela seção anglo saxônica do congresso. Sob o título "Atas do Congresso de Milão", o relatório de Kinsey foi publicado na Série Histórica do INES (Instituto Nacional de Educação de Surdos), em 2011. Já o texto oficial das atas, redigido pelo secretário italiano do congresso, professor Pasquale Fornari (1837-1920), ainda não traduzido para língua portuguesa, pode ser lido no original italiano ou na sua versão francesa.

Outros dois textos que retratam "Milão" retomam as ideias principais do evento, mas se tornam singulares por serem relatórios de enviados ao congresso. O primeiro deles é de Adolphe Franck (1834-1926), de formação filosófica. O autor fora enviado ao evento pelo Ministro do Interior da França. O relatório elaborado por Franck foi publicado no Journal Officiel $\mathrm{n}^{\circ} 346$ de 18 de dezembro de 1880. O segundo deles, de Ernest La Rochelle (1880), trata-se de um relatório para a família Pereire que, na França, trabalhava com o método oral. Esse último relatório é bastante conciso.

Temos ainda relatórios elaborados por A. Houdin destinados ao presidente do Conselho de Instrução Pública e Belas Artes; um relatório de Peyron publicado nos Annales des maladies de l'oreille; e as notas oficiais em alemão publicadas por Treibel.

Aqui nos deteremos nos quatro primeiros documentos que nos oferecem registros do vivenciado em "Milão": Fornari; Kinsey; Franck e La Rochelle. Como o texto de Fornari é, desproporcionalmente, mais amplo, a ele nos remetemos com mais frequência.

Cada um dos documentos atende, de alguma maneira, aos interesses daquelas pessoas que participaram do Congresso citado. Assim, acreditamos que, ao aproximarmos entre si os quatro documentos, nos deparamos com o monumento "Milão". 
Consideramos "Milão" como um monumento pois, como nos aponta Le Goff (2013), por esses documentos em análise podemos nos aproximar de homens e mulheres, de suas ideias, de seus desejos e de suas realizações.

Para a realizar essa análise, é interessante lançar um olhar sobre as fontes partindo da noção de documento/monumento nos escritos de Le Goff (2013, p. 485):

O monumento tem como características o ligar-se ao poder de perpetuação, voluntária ou involuntária, das sociedades históricas (é um legado à memória coletiva) e o reenviar a testemunhos que só numa parcela mínima são testemunhos escritos. [...] $\mathrm{O}$ documento não é qualquer coisa que fica por conta do passado, é um produto da sociedade que o fabricou segundo as relações de forças que aí detinham um poder. Só uma análise do documento enquanto monumento permite a memória coletiva recuperá-lo e ao historiador usá-lo cientificamente, isto é, com pleno conhecimento de causa.

Aproximarmo-nos de "Milão" como um monumento com vários documentos significa não nos atermos apenas às atas do Sr. Kynsey traduzidas para a Língua Portuguesa, pois concordamos com Foucault que os problemas da história podem se resumir a uma só frase: "questionar o documento". Assim, "o documento não é o feliz instrumento de uma história que seja em si própria e com pleno direito, memória: a história é uma certa maneira de uma sociedade dar estatuto e elaboração a uma massa documental de que não se separa" (FOUCAULT, 2005, p. 8). Por isso a inquietude ao nos aproximarmos desse congresso por outros documentos ainda não traduzidos para o Português.

Para além disso, olhamos para os documentos de eventos anteriores, como 1878 e 1879, e para os posteriores (até os anais do Congresso de Paris de 1900). Todos esses eventos contribuíram para a leitura e para mais interrogações que fizemos aos documentos de "Milão", sobretudo a versão oficial de Fornari que, com mais de 500 páginas, detalha todas as discussões do evento.

\section{Por que um congresso em Milão?}

Para refletir sobre "Congresso de Milão" (1880), é preciso compreender a estratégia dos defensores do Método Oral Puro. No ano anterior ao evento, 
quando se realizou o Congresso Nacional de Lyon (1879), evidenciou-se que o debate acerca dos métodos, já iniciado no Congresso de Paris (1878), poderia perder forças caso permanecesse em território francês. Ali amplamente se praticava o método misto, que combinava a prática da articulação com o uso de sinais. Além disso, na França era tida a figura de L'Épée como a de um defensor do uso de sinais. A escolha de Milão, na Itália, como sede do evento tinha, portanto, objetivos bastante precisos.

Em Milão encontravam-se duas escolas oralistas: o Instituto Real e o Instituto dos Surdos-mudos Pobres de Campanha. O Instituto Real era mantido pelo Estado enquanto o outro era administrado pela diocese de Milão. Dessa forma, sediou-se o congresso a fim de que os participantes pudessem ver o funcionamento do "método oral puro" e foram reservados dois dias do evento a fim de que os congressistas pudessem não só visitar, mas também acompanhar exames de alunos surdos-falantes educados nos institutos.

Nas páginas iniciais do documento oficial organizado por Fornari (1881), são apresentados os conteúdos ensinados aos surdos dos institutos de Milão, permitindo-nos ver o quanto se preconizava no local o aprendizado da língua oral, com muitas referências às questões ligadas à pronúncia e articulação das palavras. Além disso, os conteúdos para cada grupo de alunos tinham também temas religiosos a serem abordados, baseados em fatos bíblicos ou na história da Igreja Católica.

Para Foucault, a questão da verdade sempre foi muito importante. Muito mais do que discutir se algo é verdade ou não, a questão passa muito mais sobre o como as verdades são constituídas.

Ora, o fato de Milão ser escolhida possibilitava criar aquilo que chamamos aqui de "verdade testemunhal". Desde Paris, em 1878, aparentemente, a "verdade oracular" oriunda dos especialistas ainda não bastava para que se decidisse pelo método oral puro como o verdadeiro e melhor método de ensino da palavra ao surdo. Ainda havia debates profundos, como constam nos documentosmonumentos de Paris (1878) e sobretudo em Lyon (1879).

Para ilustrar a passagem da descoberta do saber que não se sabe ainda, a figura de Édipo, da tragédia grega escrita por Sófocles, é evocada por Foucault. Ao descobrir, com a investigação, a verdade, Édipo ilustra isso bem, porque passa da condição do que não sabe para a do que sabe.

Foucault (2010) analisa a condição da verdade que rodeia a vida de Édipo: a verdade oracular que define tudo, que é inquestionável e externa porque é a fonte da verdade simplesmente por ser. É definida como verdade porque a enuncia vinda de alguém ou de algo.

O oráculo, de Delfos, define a própria existência de Édipo e as verdades nessa tragédia grega são enunciadas por meio da narrativa. Porém, ela não basta. 
Ela não consegue resolver a questão da maldição em Tebas, mesmo quando Tiresias confronta Édipo com sua própria verdade.

Essa verdade de Tiresias é uma verdade exterior. Ele mesmo é um adivinho e sua verdade é externa. Ele não afirma diretamente na história: "Tu que mataste Laio". Mas diz: "Prometeste banir aquele que tivesse matado; ordeno que cumpras teu voto e expulses a ti mesmo".

Isso tudo foi dito, segundo Foucault (2003), como prescrição, como algo do futuro, predição. Por isso, uma nova constituição de verdade é evocada nesse espaço: a verdade dita por uma testemunha. "[...] falta, entretanto, alguma coisa que é a dimensão do presente, da atualidade, da designação de alguém. Falta o testemunho do que realmente se passou [...] do que realmente aconteceu" (FOUCAULT, 2003, p. 35).

Quando o servo de Laio é convocado por Édipo a dizer a verdade e diz: eu vi, eu estava lá, eu cumpri a ordem de Laio (o rei de Tebas), uma nova constituição dessa verdade é, então, celebrada. A verdade subjetiva, aquela que pode ser afirmada por um "eu". A verdade "[...] que se forma pouco a pouco, pedaço por pedaço, elemento por elemento, é um dizer verdadeiro que obedece à forma, à lei e às exigências da memória, e é um dizer verdadeiro que não se pronuncia e que surge de quem o viu pelos próprios olhos" (FOUCAULT, 2010, p. 51). A essa verdade Édipo não resiste e se entrega à autopunição.

$\mathrm{O}$ fato de ter dois institutos em Milão que já trabalhassem com o método oral puro pôde oferecer aos participantes uma espécie de "testemunho" do que poderia ser ensinado aos surdos por meio de sua aplicação, incluindo nesse "testemunho" exposições e mostras sobre o como fazer. Não é sem razão que Franck manifesta sua admiração ante as práticas das escolas de Milão:

Todas as ordens são dadas pela palavra, todas as perguntas são feitas em viva voz, e as primeiras são seguidas por uma execução, as segundas por uma resposta tão rápida como se elas chegassem uma e outra para a inteligência pelo ouvido. O ouvido é aqui substituído pelos olhos e a mímica externa pela mímica interna dos órgãos vocais, exercida, por força da paciência e de acordo com as regras experimentadas, para tornar o surdo-mudo em um falante surdo. $\mathrm{O}$ surdo-falante não ouve sua própria palavra mais do que a dos outros; mas a de outros ele lê em seus lábios (FRANCK, 1880, p. 16-17, tradução nossa).

Apesar de o congresso ter se dado em Milão, depois dos italianos, a maior nação participante era a França, país em que as decisões viriam a ter maior 
impacto. Essa forte presença foi possível porque a família Pereire, que havia instituído um colégio na França que trabalhava com o método oral, patrocinou a viagem de muitos professores franceses. Grande parte dessa comitiva francesa era composta pelos Irmãos de São Gabriel, administradores de um colégio que assumiria o método oralista.

Outro fato que nos ajuda a compreender a escolha da sede é que também em Milão aconteceram outros dois eventos que discutiram a surdez.

Entre os dias 02 e 05 de setembro de 1880, ocorreu o "Primeiro Congresso Internacional de Laringologia" e, entre os dias 06 e 09 de setembro, mesmos dias do "Congresso de Educação de Surdos", ocorreu o "Segundo Congresso Internacional de Otologia" (BENVENUTO, 2010). Notamos que não se tratou de uma coincidência, mas sim de uma organização que favoreceu o encontro dos professores de surdos com personalidades que estudavam acerca da surdez e tinham também contribuições a apresentar sob a perspectiva dos métodos. Por esses movimentos se validaria a decisão de "Milão".

\section{Os conteúdos de Milão: para além da oposição entre oralismo e língua de sinais}

Notadamente, os trabalhos que discutem sobre o "Congresso de Milão" abordam como nele se explicitou a polarização entre o método oral puro e o método misto. Essa oposição traduziu-se numa compreensão bastante difundida, posteriormente, da oposição entre oralismo e línguas de sinais.

Acreditamos que essa questão já foi suficientemente refletida (ROCHA, 2010). Contudo, há outros elementos presentes no corpus monumental do "Congresso de Milão" que nos auxiliam a compreender como, para além da oposição entre métodos, há espaços para outras discussões. O debate sobre os métodos toma a maior parte do tempo do congresso, fazendo, inclusive, com que se inverta a ordem do programa previsto em carta-convite do evento. Evidenciase, portanto, que não havia apenas um método, mas métodos.

As críticas ao método oral são refutadas por diversos expositores mostrando uma retórica que procura situar os congressistas na temática que já lhes é familiar, mas corroborando para elaborar argumentos em defesa de suas posições. De forma retórica, portanto, os congressistas elencam, por vezes, as acusações ao método oral puro e procuram fundamentar suas vantagens em relação ao método misto. Elabora-se assim um discurso que refuta as oposições e delineia o melhor a ser aceito por todos. 
Foucault nos fala de procedimento de controle do discurso:

[...] eles podem ser externos, quando realizam a submissão da dimensão do discurso relativa ao poder e ao desejo, são eles: a palavra proibida, a separação entre normal e anormal e a vontade de verdade; podem ser internos, quando dizem respeito à sujeição do acontecimento e do acaso, tais quais: o autor, o comentário e a disciplina; e podem ser também o grupo de controle dos sujeitos que pronunciam o discurso, como os sistemas de restrição que são exercidos nos rituais da palavra, nas sociedades do discurso, nas doutrinas e mesmo no próprio sistema de ensino (FOUCAULT, 2009, p. 39-44).

As críticas ao método misto são uma constante. Elas surgem nos diversos discursos como maneira de mostrar a necessidade e a urgência de uma mudança metodológica.

Várias outras questões perpassam os discursos que procuram justificar a opção pelo método oral. Pode-se perceber que, durante todo o "Congresso de Milão", houve grande influência da "Sociedade de Formação de Professores para Surdos e Difusão do Sistema 'Alemão'", convidada para apresentar reflexões. Os propósitos oralistas do grupo eram articulados da seguinte maneira:

Duas instituições eram ofertadas pela Sociedade de formação de professores: a) Instituto de formação - destinado à formação de professores, governantas e pessoas relacionadas com o surdo, admitindo somente estudantes do sexo feminino; b) Escola - destinada a alunos de pais instruídos. Embora se definisse como instituição não confessional, a escola vinculada à Sociedade de formação para professores de surdos seguia os princípios da Igreja na Inglaterra, associando à formação instruções morais e religiosas. O método utilizado na escola se baseava na articulação da leitura labial, da leitura e da escrita, sendo proibido o alfabeto manual e o uso de sinais (RODRIGUES; VIEIRA-MACHADO, 2018, p. 64).

Os trabalhos apresentados tinham por objetivo convencer a todos da eficácia do método "alemão". O uso de testemunhos foi fundamental para a tessitura dessa verdade. Por exemplo, temos o testemunho da Sra. John Ackers, que abordou o "Desenvolvimento mental dos surdos com base no sistema 
'alemão"', mostrando como compreendia a relevância do método oral a partir de sua perspectiva de mãe de uma criança surda e que visitou diversas instituições de educação de surdos.

Outra testemunha, Suzana Hull, professora de surdos, relatou "Minha experiência com diversos métodos educacionais para crianças surdas de nascença", evidenciando sua opção por abandonar o método misto, com o qual trabalhou por muitos anos, por considerar que o método oral era mais eficaz e permitia a socialização dos surdos (KINSEY, 1880).

Kinsey discorreu sobre "A educação de surdos" como objeto de suas observações, procurando responder às questões do congresso. Já J. Ackers refletiu sobre "Os surdos e os benefícios do sistema 'alemão' na vida posterior", afirmando o quanto tal método asseguraria um futuro mais digno para os surdos. E. Symes-Thompson discursou sobre "A saúde dos surdos-mudos", evidenciando a proximidade entre medicina e educação de surdos, bem como sua perspectiva eugenista quando afirma que a natureza deficiente do surdo poderia ser corrigida e que com isso se emanciparia esse sujeito. David Buxton discorreu sobre "Fala e leitura labial para surdos: testemunho de um professor sobre o sistema 'alemão"'. O tom mais testemunhal dessa última reflexão condizia com a construção de uma verdade que deveria ser aceita porque já haveria evidentes resultados (KINSEY, 1880).

Esses textos dos difusores do método oral puro 'alemão' foram compilados nos anexos do relatório elaborado por Kinsey. Os mesmos textos aparecem no documento de Fornari na sequência das discussões das sessões do congresso - com exceção dos textos de Asckers e Buxton que estão nos apêndices, o que permite sua melhor compreensão no contexto em que foram lidos.

Os aspectos pedagógicos ficam muito evidentes nos registros do congresso. Se a decisão do congresso teria ressonâncias mundiais, era necessário ter clareza do que se praticaria, uma vez que, nas críticas ao método oral, se recordava que muitos fizeram adaptações prejudiciais. O método estava previamente escolhido, mas se fazia premente esmiuçá-lo. Se visibiliza aí como certa cientificidade é aplicada à compreensão do método.

No documento elaborado por Fornari, lê-se uma breve carta enviada por Felice Carbonera, surdo-falante defensor do método oral. Carbonera recorda ser o primeiro surdo educado pelo método articulado em Milão, por volta do ano de 1847. O homem insiste sobre os benefícios que sente ter recebido graças à oralização, fala da eficácia das poucas lições recebidas e conclama: 
Portanto, desejoso de que todos os meus irmãos da desventura possam aproveitar a mesma vantagem, espero que todos os notórios senhores instrutores de surdos e mudos, assiduamente envolvidos em tal instrução de linguagem articulada e no curso de estudos, nunca esqueçam de corrigir e melhorar a palavra de seus alunos, para que possam alcançar o desejado conforto moral e social (FORNARI, 1880, p. 411, tradução nossa).

A leitura da carta de Carbonera manifesta como também havia, entre os surdos, defensores do método articulado e, além disso, como esses indivíduos se dispunham a propagar as vantagens desse método. Parece-nos mais um elemento para a constituição de uma verdade já que, a partir do relato de um surdo sobre a eficácia com que o "irmão de infortúnio" fora salvo do alijamento social, impõe-se a metodologia a outros na mesma condição.

Fornari também apresenta nos apêndices do seu documento outros estudos e memórias que foram apresentados no congresso: $\mathrm{O}$ texto de J. Ackers, que procura responder de forma organizada e metódica a primeira questão que fora proposta aos congressistas sobre os método; Brambilla, professor do Instituto de Milão que reflete sobre "A educação do surdo por meio da palavra", reforçando os aspectos pedagógicos a serem observados na prática do método oral; e David Buxton, que procura responder em seu texto às diversas questões do congresso.

Na mesma perspectiva, encontra-se o texto enviado por Dionisio Cozzolino. Ciente das eventuais dificuldades a serem enfrentadas na implementação do método oral, Cozzolino conclui sua reflexão da seguinte maneira:

A primeira questão especial é que os surdos-mudos treinados com o método de articulação esquecerão facilmente, após deixar a escola, a maior parte do conhecimento adquirido; pois a linguagem natural dos surdos-mudos é a dos gestos, e a escrita como forma racional de pensamento se apresenta aos surdos-mudos com menos dificuldade do que a linguagem articulada. Em conversação com os oradores, eles preferiram a linguagem mimética e a linguagem escrita. De tudo isso, temos de reprovar os mestres, que, na medida em que os surdosmudos aprenderam a palavra falada, não restringiram o uso da mímica. Assim, para remediar esses defeitos, o mestre terá que usar apenas a articulação, proibindo estritamente o mimetismo, continuamente acostumando os alunos à linguagem oral, até que eles se esqueçam da linguagem mímica, e que o hábito seja convertido em natureza (FORNARI, 1880, p. 414, tradução nossa). 
Evidencia-se na conclusão de Cozzolino que é próprio do surdo utilizar o gesto, contudo os professores deveriam se esforçar para que acontecesse certa conversão do surdo, abandonando o que lhe era peculiar para assumir uma nova linguagem.

Em outro texto, enviado por Haerne, "Ensinamento de surdos-mudos depois do método combinado de articulação e mímica" aparecem indícios de um histórico de opções, também dadas em eventos nacionais ou internacionais, favoráveis ao método combinado. Apesar de reconhecer o valor dos sinais na vida do surdo, o texto sugere a relevância do método oral:

Em geral, é a utilidade da articulação que é mais difícil de fazer os alunos entenderem. Mas, para ter sucesso nisso, é necessário insistir nessa verdade incontestável de que é apenas através da fala articulada que realmente se pertence à sociedade e que sem ela se considera um estranho no próprio país. Devemos mostrar que, sem negligenciar os sinais, que são a linguagem natural dos surdos-mudos, eles devem cultivar com zelo a articulação, que é para eles, como para os outros cidadãos, a língua nacional e os meios comunicação mais valiosa que eles devem cultivar constantemente, de modo a não perder seu uso por negligência ou esquecimento, como é frequentemente visto (FORNARI, 1880 , p. 424, tradução nossa).

Émlle Grosselin, promotor do método fonomímico, em sua comunicação sobre a questão dos métodos, defende sua proposta numa possível conciliação que visa a fala dos surdos. Hirsch, diretor da Instituição de surdos-mudos de Rotterdam, aborda diversas questões no texto enviado ao congresso: indica as vantagens do método oral em comparação com o de sinais; explica o que é o método oral puro e sua distinção em relação ao método misto; explica a separação entre sinais metódicos e naturais; esclarece os meios naturais para os surdos conhecerem a língua; aponta o avanço dos surdos ensinados pela articulação em relação a outros; a organização de turmas de surdos nos institutos.

Auguste Houdin, diretor do Instituto de Surdos de Paris-Passy, discute as principais questões do congresso. Algumas questões sobre métodos são analisadas por Rossler, diretor do Instituto de Surdos de Hildescheim. Ainda sobre as questões do programa do congresso, temos o texto enviado por Dr. Treibel, diretor de uma instituição em Berlim, e o texto de Léon Vaïsse, diretor honorário do Instituto Nacional de Paris. Ambos defendem o método oral puro. 
Nos apêndices propostos por Fornari, podemos ler na íntegra o texto de Magnat, diretor do Instituto Pereire em França. Havia, sem dúvida, uma decisão prévia em favor do método oral, todavia o exercício de criticar o método misto e enaltecer o método oral puro, principalmente a partir de testemunhos, parece ter por finalidade fundamentar a nova verdade. Para isso, até mesmo a figura de L'Épée, classicamente associada à defesa do uso de sinais, é também incorporada como um reconhecedor da necessidade da oralização.

Agindo assim, os congressistas arregimentam para o método oral a figura imponente do defensor dos surdos. Após apresentar um quadro comparativo entre o que era ensinado pelo método de sinais no Instituto Nacional de Paris e o que era ensinado pelo método oral no Instituto Pereire, realçando a desproporcionalidade da superioridade do método oral, Magnat retoma uma frase de L'Épée e a utiliza em favor da oralização:

"O único meio de devolver totalmente o surdo-mudo à sociedade é por meio do aprendizado da escuta por meio dos olhos e a se exprimir de viva voz", disse o abade L'Épée. E, com efeito, a fala não é a linguagem de todos, tanto do sábio quanto do ignorante, tanto do mestre quanto do trabalhador, tanto do rico quanto do pobre? (FORNARI, 1880, p. 495, tradução nossa).

Vozes dissonantes também estavam presentes em Milão como se pode ler na resposta de Edward Gallaudet a uma das questões do congresso, pronunciando-se a favor do "método combinado". Em seu texto "Sobre o ensinamento secundário e superior dos surdos-mudos", Gallaudet mostra como, nos Estados Unidos, houve um avanço ao se ofertar cursos de nível secundário e superior para os surdos e como tal tarefa permanecia ainda a ser realizada na Europa:

Pois, mais que os outros, [os surdos] precisam recorrer aos tesouros do conhecimento, a fim de compensar a privação dos dois vínculos que mais estreitamente ligam o ser interior à natureza, e também, a fim de lhes trazer consolação sem número que não podem deixar de experimentar no íntimo intercâmbio das obras-primas da mente humana (FORNARI, 1880 , p. 435, tradução nossa). 
Concluímos que, para além da oposição entre sinais e oralização, nos documentos há uma série de outras temáticas a ela relacionadas, incluindo a discussão sobre como a verdade foi construída e pavimentada para que houvesse uma massiva votação a favor do método oral puro.

\section{As bases para um pensamento dominante}

Não temos a pretensão de esgotar todos os elementos que sustentaram a constituição da verdade de "Milão" (1880), mas queremos evidenciar aqueles que mais foram apresentados nas falas dos participantes do congresso.

Numa Europa marcadamente católica e que ainda procurava se mostrar potente diante das investidas protestantes, o "Congresso de Milão" é também expressão de uma fundamentação religiosa versus o advento da perspectiva científica darwinista. Grande parte dos congressistas era composta por religiosos católicos. Por isso, mesmo que a busca de testemunhos do método oral puro evidencie a escolha de Milão, a verdade oracular ganha força na disputa entre religiosos e cientistas. Desde a abertura do evento, perpassando diversas exposições e debates, recorre-se aos textos bíblicos para fundamentar a argumentação em defesa do uso da palavra.

Na tradição judaico-cristã, a palavra é expressão da força divina capaz de criar e ordenar todas as coisas. No relato bíblico, o Criador faz uso da palavra para dar vida às coisas.

Lê-se na semana da criação uma série de ações em que Deus diz: "Façase...!" Se constituído à imagem e semelhança do Criador, como poderia o humano não falar? A palavra é tida como expressão de um dom divino.

Dr. Zucchi, presidente do conselho diretivo do Instituto Real dos Surdosmudos de Milão, representante do Ministro da Instrução Pública e da Associação Pedagógica de Milão, reafirma a palavra como expressão da força divina nos seguintes termos: "a palavra viva, que é o privilégio do homem, o veículo único e seguro do pensamento, o dom de Deus, do qual pudemos dizer com verdade: "Luz da alma é a palavra e a alma é na terra a luz do pensamento divino"” (FORNARI, 1880, p. 95, tradução nossa).

Na sequência do mito da criação, o capítulo 2 de Gênesis nos fala de como Deus convida Adão, o primeiro humano, a colaborar na obra da criação. Esse argumento usado por um dos congressistas parece indicar a impossibilidade de se atingir a plena humanidade sem o uso da fala. É, pois, o ato de falar que permite ao humano distinguir-se daqueles a que ele nomeia. Balestra, sacerdote 
diretor do Instituto de Surdos-mudos de Como (Itália) faz de tal argumento bíblico uma prerrogativa de veracidade para o método oral puro:

Todos vocês falaram admiravelmente; mas eu quero sanar uma lacuna. Primeiro: método objetivo. Deus, depois de criar o homem, deu-lhe a palavra e Adão deu um nome a todos os animais; foi, portanto, o próprio Deus que nos forneceu o método oral objetivo (FORNARI, 1880, p. 261, tradução nossa).

Como se tratou de um evento com grande participação de representantes católicos, há também, na argumentação, certo apelo ao carisma missionário. Recorre-se ao texto bíblico em que Jesus envia seus discípulos para então sugerir a necessidade de que o surdo fale e possa, portanto, comunicar a boa nova recebida. $\mathrm{O}$ “efatá!" missionário se constitui como elemento que corrobora para a escolha do método em função de uma possível confissão:

Somos todos filhos do mesmo Cristo, que nos deu o exemplo: "fez os mudos falarem", e o ministro de Cristo deve abrir a boca para o mudo. As escrituras também dizem: "Ide e ensinai", esse é o nosso programa. Nós também somos surdos-mudos no meio da sociedade que não nos entende; e é doloroso saber que existem alguns confrades que não nos entendem. Acrescentarei que é necessário para um padre católico que os mudos saibam falar, por causa do que confessamos, e que no campo o sacerdote entenderá todo o contrário que o pobre surdo-mudo lhe dirá por sinais. Por favor: Vote na palavra, sempre na palavra (FORNARI, 1880, p. 154, tradução nossa).

Junte-se à base bíblica uma certa fundamentação filosófica. A maior crítica feita ao método misto sob essa perspectiva é que os sinais impedem os surdos de fazerem uso da abstração. Ao longo dos discursos, exemplifica-se que o surdo-falante, diferente daquele educado pelo método misto, será capaz de compreender conceitos metafísicos como existência, divindade etc.

Pensar seria típico do humano, mas algo a que o surdo somente iria alcançar caso conseguisse falar. Bouchet, capelão dos surdos em Morbihan (França), referese a isso: "A fala, de fato, é o veículo natural do pensamento; a palavra criou a ideia em todas as coisas do universo. Toda ideia, todo sentimento, se expressa pela fala. Viva a palavra!” (FORNARI, 1880, p. 147, tradução nossa). Tarra afirma que: 
O surdo-mudo, porque ele é um ser inteligente, tem o pressentimento, eu ia quase dizer a necessidade da ideia. Mas qual é a ideia? A ideia é o conhecimento intelectual do ser; existe, portanto, apenas sob a condição de estar completo. A ideia não é o conhecimento de uma parte do ser em detrimento das outras partes, mas a posse intelectual, se assim posso dizer, de todo o ser; substância, forma, elementos. Toda ideia que não abraça a plenitude do ser é apenas uma ideia mutilada, enfim, uma ideia falsa, a inteligência que a concebe e a carrega, sofre; sofre porque espera e deseja algo de que necessita, e que será como seu complemento necessário. [...] Agora pergunto-lhes, qual é a expressão, palavra ou sinal, que dá à inteligência humana as mais completas e, consequentemente, as mais verdadeiras ideias? Eu não hesito em responder, senhores: obviamente é a palavra. Por quê? Porque a palavra que não tem forma material, não tem limites; é tão vasta quanto a ideia, e a abraça inteiramente; ela revela todos os seus elementos de uma só vez (FORNARI, 1880, p. 239-240, tradução nossa).

É necessário distinguir o humano dos animais e isso é feito pelo uso da palavra. Importante notar como, ao fazer certo movimento que insiste no uso da palavra, confirma-se uma distinção darwinista sobre evolução, mas ao mesmo tempo se assume a postura do naturalista britânico de que as expressões faciais e gestos estariam numa cadeia evolutiva. Por isso também o uso dos gestos era visto como tão ameaçador, pois poderia corromper a humanidade evoluída. Arnold, representante da Inglaterra, explicita essa noção nos seguintes termos:

Repito: não foi encontrado nenhum símbolo de pensamento que possa ser comparado a sons articulados. Ouvimos ou sentimos os sons, mas nunca podemos transformá-los em imagens materiais. Eles não ocupam lugar no espaço. E essa é a razão pela qual eles foram escolhidos por natureza ou pelo Criador onisciente para o tempo em que nos tornamos capazes de pensar e, como resultado, de falar. Os signos são representações ideográficas, símbolos ou hieróglifos derivados da forma, da cor ou da magnitude das coisas visíveis que eles afirmam fornecer na ausência de si mesmos. Em cada um há um objeto mental ou uma ideia sugerida pela coisa da qual é o signo (FORNARI, 1880, p. 141-142, tradução nossa).

A ideia de caridade está também presente nas argumentações. Os debates do momento assinalam que fará um grande bem aos surdos ensinar-lhes a falar. Bem que não se realiza plenamente quando se utilizam dos sinais. Em nome de uma 
futura autonomia e participação social, procura-se incentivar os participantes a que a decisão pelo uso da palavra seja aquela mais condizente com o propósito do evento: "melhoramento da sorte dos surdos".

A expressão comemorativa "Viva la parola" ("Viva a palavra"), presente em diversos momentos do texto, evoca o sentimento de contentamento por parte dos congressistas ao decidirem pelo uso do método oral. No relatório de $\mathrm{La}$ Rochelle, mais conciso e organizado em torno das deliberações, há um conjunto de expressões similares que expressam o sentimento de triunfo por parte dos oralistas: "vitória que está se preparando"; "Seu triunfo é afirmado"; "Esta resolução foi votada com entusiasmo"; "A bandeira da palavra"; "Desaparece, simulacro vaidoso! O verdadeiro Deus se tornou conhecido"; "O mal é o silêncio"; "Vitória" (LA ROCHELLE, 1880).

\section{Considerações finais}

"Milão" ainda tem muitos elementos a nos provocar. Acreditamos que, nesse congresso de 1880 , se operou a constituição de uma verdade por parte de um determinado grupo por meio da busca de testemunhos que evidenciassem a suposta superioridade do método oral puro sobre o método misto, ou mesmo testemunhos que apontassem para/ indicassem a eliminação do uso dos sinais na educação dos surdos para que se fortalecesse a verdade oracular, verdade tal produzida a partir da argumentação fundamentada em textos tidos como sagrados como numa pretensa cientificidade ligada à questão metodológica. E ainda com apoio financeiro por parte da família Pereire para que se pudesse instaurar depois do evento uma prática condizente com a verdade escolhida, que foi a superioridade do método oral puro.

O corpus documental sobre o qual nos debruçamos permite compreender o quanto o evento se deu em meio à complexidade de se elaborar uma dada verdade. As falas dos participantes apontam para pontos de encontro, mas também para dissonâncias, ou seja, mesmo entre aqueles que já consideravam a questão da articulação como o método ideal para se educar os surdos, havia questões a serem resolvidas. Dessa maneira, podemos considerar que as discussões de "Milão" mostram como se pode "afinar" uma orquestra com práticas até então variadas.

Apesar de não termos nos detido nas deliberações do evento - bastante conhecidas por aqueles que estudam a história da educação de surdos -; a escolha do método oral como melhor método teve impactos futuros que não são de fácil verificação no corpus analisado. Houve sim uma decisão a 
favor do uso do método oral puro; mas ela se concretizou imediatamente nos diversos institutos ao redor do mundo? Como "Milão" foi recebido por aqueles que não estavam representados no congresso? A opção pelo método oral em "Milão" pode realmente ser tida como um "extermínio" do uso de sinais? Em relação a essa última problematização, parece-nos que não. Uma análise de documentos de outros congressos do final do século XIX aponta-nos para isso (RODRIGUES, 2018).

Essa aproximação que fizemos aos textos de "Milão" deixa entreabertas questões que exigem aprofundamento. Como ler um documento do século XIX e interpretá-lo para permitir que ele diga algo ao nosso presente? Considerando que algumas abordagens da história da educação de surdos veem em "Milão" um prenúncio do antagonismo entre surdos e ouvintes em função do antagonismo lá explicitado entre os métodos, como se aproximar desse documento e colher as outras riquezas que nele nos apresentam?

"Abre-te!" Parece-nos condizente com a construção de uma verdade para operar sobre as pessoas de modo a fazê-las também dizer aquilo que foi de modo incontestavelmente aceito. O "abre-te" cristão direcionado aos surdos via oralização pode ter significado uma série de cerceamentos, mas também uma abertura para outras práticas que escapavam ao governamento imposto. Paradoxalmente, talvez em "Milão", ao se preconizar o ideal da oralização, tenham sido abertos horizontes para um rompimento da assistência destinada aos surdos e um incipiente movimento para a emancipação daqueles que passariam a ser compreendidos como sujeitos a serem educados. Milão encontrase aberto aos nossos olhares problematizadores. Ou melhor, encontra-se a nos pedir: "Abra-me!"

\section{REFERÊNCIAS}

BENVENUTO, Andrea. L'autre Milan 1880: le congrès international d'otologistes et l'instruction physiologique. La nouvelle revue de l'adaptation et de la scolarisation, Paris, n. 49, jan./mar. 2010.

CÂMARA, Leandro Calbente. A invenção da educação dos surdos: escolarização e governo dos surdos na França de meados do século XVIII a meados do século XIX. Tese (Doutorado em Educação) - Universidade Estadual de Campinas, Campinas, 2018.

FORNARI, Pasquale. Compte-rendu du Congrès International pous l'amélioration du sort des sourds-muets tenu à Milan du 6 au 11 septembre 1880. Roma: Héritiers Botta, 1881. 
FOUCAULT, Michel. A verdade e as formas jurídicas. Rio de Janeiro: NAU, 2003.

FOUCAULT, Michel. A arqueologia do saber. Rio de Janeiro: Forense Universitária, 2005. FOUCAULT, Michel. A ordem do discurso. Tradução de Laura Fraga de Almeida Sampaio. 18. ed. São Paulo: Edições Loyola, 2009.

FOUCAULT, Michel. Do governo dos vivos: curso no College de France, 1979-1980 (excertos). Tradução, transcrição e notas de Nildo Avelino. São Paulo: Centro de Cultura Social; Rio de Janeiro: Achiamé, 2010.

FOUCAULT, Michel. A Coragem da Verdade: O governo de si e dos outros II. Curso no Collège de France (1983-1984). Tradução de Eduardo Brandão São Paulo: WMF Martins Fontes, 2014a.

FOUCAULT, Michel. A arqueologia do saber. Tradução de Luiz Felipe Baeta Neves. 8. ed. Rio de Janeiro: Forence Universitária, 2014b.

FRANCK, Adolphe. Rapport au Ministère de l'Inérieus et des Cultes sur le Congrès de Milan. Les Essarts-le-Roi: Edition du Fox (org.). 1880. Fac-símile- domínio público. Disponível em: http://www.2-as.org/editions-du-fox/. Acesso em: março 2019.

LA ROCHELLE, Ernest. Le Congrès de Milan pour l'amélioration du sort des sourdsmuets. Rapport adressé à $\mathrm{M}$. Eugène Pereire - Président du Comité d'organization. Paris: M. Saint-Jorre, 1880. Paris: [S. n.], 1880. Les Essarts-le-Roi: Edition du Fox (org.). Fac-símile - domínio público Disponível em: http://www.2-as.org/editions-du-fox/. Acesso em: março 2019.

LE GOFF, Jacques. História e memória. Campinas: Editora da UNICAMP, 2013.

KINSEY, Arthur Alfred. Relatório das leituras apresentadas durante o Congresso Internacional de educação para surdos. Realizado em Milão de 6 a 11 de setembro de 1880. Extraído das minutas oficiais em inglês. Londres: Allen \& Co., 1880.

MILÃO. Atas do congresso de 1880. Rio de Janeiro: INES, 2011. (Série Histórica, v. 2).

PARAÍSO, Marlucy Alves. Metodologias de Pesquisas Pós-Críticas em Educação e Currículo: trajetórias, pressupostos, procedimentos e estratégias analíticas. In: MEYER, Dagmar Estermann; PARAÍSO, Marlucy Alves (org.). Metodologias de pesquisa póscríticas em educação. Belo Horizonte: Mazza Edições, 2012. p. 23-45.

ROBIN, Régine. A memória saturada. Campinas, São Paulo: Editora da Unicamp, 2016.

ROCHA, Solange Maria da. Memória e história: a indagação de Esmeralda. Petrópolis: Arara Azul, 2010. (Caderno Acadêmico 1). 
RODRIGUES, José Raimundo; VIEIRA-MACHADO, Lucyenne Matos da Costa. A participação da Sociedade de Formação de Professores para Surdos e Difusão do Sistema "Alemão" no Congresso de Milão (1880). In: VIEIRA-MACHADO, Lucyenne Matos da Costa; BARBOZA, Felipe Venâncio; MARTINS, Vanessa Regina de Oliveira. Pesquisas em educação de surdos, tradução, interpretação e linguística de línguas de sinais: tecendo redes de amizade e problematizando as questões do nosso tempo. Campos dos Goytacazes: Brasil Multicultural, 2018. p. 61-70.

RODRIGUES, José Raimundo. As seções de surdos e de ouvintes no congresso de paris (1900): problematizações sobre o pastorado e a biopolítica na educação de surdos. Dissertação (Mestrado em Educação) - Universidade Federal do Espírito Santo, Vitória, 2018.

Texto recebido em 18/01/2020.

Texto aprovado em 27/11/2020. 